\title{
Correlation of biological serum markers with the degree of hepatic fibrosis and necroinflammatory activity in hepatitis $\mathrm{C}$ and schistosomiasis patients
}

\author{
Clarice Neuenschwander Lins de Morais ${ }^{1 /+}$, Bruno de Melo Carvalho ${ }^{1}$, \\ Wlademir Gomes de Melo', Fábio Lopes de Melo', Edmundo Pessoa de Almeida Lopes², \\ Ana Lúcia Coutinho Domingues², Norma Jucá², João Roberto Maciel Martins ${ }^{3}$, \\ George Tadeu Nunes Diniz ${ }^{1}$, Silvia Maria Lucena Montenegro ${ }^{1}$
}

\begin{abstract}
${ }^{1}$ Departamento de Imunologia, Centro de Pesquisas Aggeu Magalhães-Fiocruz, Av. Moraes Rego s/nº, 50670-420 Recife, PE, Brasil ${ }^{2}$ Universidade Federal de Pernambuco, Recife, PE, Brasil ${ }^{3}$ Universidade Federal de São Paulo, Escola Paulista de Medicina, São Paulo, SP, Brasil

Liver biopsy is the gold-standard method to stage fibrosis; however, it is an invasive procedure and is potentially dangerous. The main objective of this study was to evaluate biological markers, such as cytokines IL-13, IFN- $\gamma$, $T N F-\alpha$ and TGF- $\beta$, platelets, bilirubins (Bil), alanine aminotransferase (ALT) and aspartate aminotransferase (AST), total proteins, $\gamma$-glutamil transferase $(\gamma-G T)$ and alkaline phosphatase $(A P)$, that could be used to predict the severity of hepatic fibrosis in schistosomiasis and hepatitis $C(H C)$ as isolated diseases or co-infections. The following patient groups were selected: HC $(n=39)$, HC/hepatosplenic schistosomiasis (HSS) $(n=19), H S S(n=22)$ and a control group $(n=13)$. ANOVA and ROC curves were used for statistical analysis. $P<0.05$ was considered significant. With HC patients we showed that TNF- $\alpha(p=0.020)$ and AP $(p=0.005)$ could differentiate mild and severe fibrosis. With regard to necroinflammatory activity, AST $(p=0.002), \gamma-G T(p=0.034)$ and $A P(p=0.001)$ were the best markers to differentiate mild and severe activity. In HC + HSS patients, total Bil ( $p=0.008)$ was capable of differentiating between mild and severe fibrosis. In conclusion, our study was able to suggest biological markers that are non-invasive candidates to evaluate fibrosis and necroinflammatory activity in $H C$ and $H C+H S S$.
\end{abstract}

Key words: biological markers - hepatic fibrosis - HC - schistosomiasis

Hepatitis $\mathrm{C}(\mathrm{HC})$ disease is an important public health problem, with a high potential for chronicity $(85 \%)$, cirrhosis and hepatocellular carcinoma (ImbertBismut et al. 2001). Hepatocellular damage occurs when the infected cell is recognized by the immune system and destroyed. This process is extremely variable and dynamic, resulting in different intensities of hepatic necrosis and inflammation. Thus, this continuous inflammatory process is responsible for fibrogenesis (Missale et al. 1996, Strauss 2001, Poynard et al. 2003). During $\mathrm{HC}$ virus (HCV) infection, male sex, age, alcohol consumption, presence of other viruses (HIV, hepatitis B virus), schistosomiasis and immunological status have been linked to histological severity (Pessione et al. 1998, Kamal et al. 2006).

Schistosoma mansoni infection is a chronic helminthic disease that develops primarily because of chronic granulomatous inflammation against parasite eggs in the liver, which results in hepatic periportal fibrosis, portal hypertension and sometimes death by digestive bleeding

Financial support: PAPES V/FIOCRUZ, CNPq (to SMLM)

+ Corresponding author: clarice@cpqam.fiocruz.br

Received 30 April 2009

Accepted 8 October 2009 of esophageal varices, present in the severe hepatosplenic clinical form. Granulomas in schistosomiasis depend predominantly on $\mathrm{CD} 4^{+} \mathrm{T}$ cells and represent a form of delayed-type hypersensitivity (Abath et al. 2006).

Andrade (1962) and Dusek et al. (1965) emphasized that the association between chronic hepatitis and schistosomiasis aggravated liver disease. Blood transfusions secondary to digestive haemorrhage due to schistosomiasis portal hypertension is one of the major causes of $\mathrm{HC}$ transmission to schistosomiasis patients in Brazil (Cid et al. 1985).

$\mathrm{HC}$ and schistosomiasis co-infection is common in many developing countries, including Brazil, and according to Kamal et al. $(2004,2006)$ shows a specific clinical, virological and histological pattern characterized by virus persistence with high HCV RNA titres and higher necroinflammatory and fibrosis scores in liver biopsies. In addition, these patients exhibit a poor interferon therapy response and accelerated hepatic fibrosis (Kamal et al. 2006).

Fibrosis is the major cause of mortality and morbidity related to both schistosomiasis and $\mathrm{HC}$, although the pattern of fibrosis and underlying immunological mechanisms are different (Abath et al. 2006).

Liver biopsy is the gold-standard method for the assessment of fibrosis; however, it is an invasive procedure and is potentially dangerous (Imbert-Bismut et al. 2001, Myers et al. 2002, Wai et al. 2003, Poynard et al. 2005). In addition, it is a costly procedure and requires a physician, support staff and an experienced pathologist. 
Furthermore, a percutaneous liver biopsy can generate sampling errors from the small size of the biopsy and variability in fibrosis interpretation, giving a static view of the necroinflammatory and fibrotic process since a liver biopsy represents only a small part of the whole organ (Lichtinghagen \& Bahr 2004).

As a result of these limitations, several studies have emerged in an attempt to develop accurate and reliable non-invasive means to assess the severity of hepatic fibrosis in $\mathrm{HC}$ patients, since knowledge of the stage of liver fibrosis is essential for prognosis and decisions on antiviral therapy (Imbert-Bismut et al. 2001, Myers et al. 2002, Poynard et al. 2002, 2005, Freeman et al. 2003, Morais et al. 2006, Gressner et al. 2007, Correia et al. 2009).

Although there is no indicator of human schistosomiasis in liver biopsy, use of non-invasive biological markers to predict fibrosis severity is important for monitoring the transition to the severe forms of the disease and prognosis of these patients. In the areas where access to health care services is limited, these markers are also essential to evaluate fibrosis regression after treatment (Burchard et al. 1998, Ricard-Blum et al. 1999, Köpke-Aguiar et al. 2002). Most of the studies regarding biological serum markers of fibrosis have focused on HC or schistosomiasis as an isolated disease. The main objective of this study was to correlate levels of biological serum markers with the prediction of clinically significant fibrosis and necroinflammatory activity in $\mathrm{HC}$ and schistosomiasis, not only as isolated diseases, but also as co-infections.

\section{PATIENTS, MATERIALS AND METHODS}

Subject selection - This study included 80 patients aged 18-65 years old, selected at the outpatient facilities of the Hospital das Clínicas da Universidade Federal de Pernambuco (UFPE), Recife, Pernambuco (PE), Brazil. The following groups were studied: HC $(n=39)$; HC plus hepatosplenic schistosomiasis (HSS) $(n=19)$ and HSS $(\mathrm{n}=22)$. Liver biopsies, ultrasonography, parasitological stool exams and blood tests for biological markers of fibrosis were performed. All patients were tested for hepatitis B (HBsAg and anti-HBc), HIV (anti-HIV) and HCV (anti-HCV) (Gretch 1997). Diagnosis of HC in patients was confirmed by detection of viral RNA (Zeuzem et al. 1994) and genotyping (Stuyver et al. 1996).

For schistosomiasis patients, the diagnosis was confirmed by ultrasonography and three parasitological stool examinations. These patients were selected after treatment; however, HC patients were selected before treatment.

Patients with the following conditions were excluded from the study: other causes of liver disease, liver transplantation, prior interferon therapy, immunosuppressive therapy, hepatitis B, HIV, insufficient liver tissue samples for staging of fibrosis and alcohol consumption (>30 g/day).

The control group $(n=13)$, ranging from 21-57 years old, was from non-endemic areas of PE and was selected at Centro de Pesquisas Aggeu Magalhães. These individuals had three negative parasitological stool examinations for $S$. mansoni, no history of contact with contaminated water and negative anti-HCV.
All patients and control group individuals signed an informed consent form and the study was reviewed and approved by the Ethical Committee of the Centro de Pesquisas Aggeu Magalhães-Fiocruz, Recife, PE, Brazil.

Fibrosis stage and necroinflammatory activity grade - HC and HC + HSS patients underwent percutaneous liver biopsy at Hospital das Clínicas da UFPE. Histological features of liver biopsy were analysed according to the Metavir scoring system (Bedossa \& Poynard 1996). Fibrosis was staged on a scale as follows: F0 (no fibrosis), F1 (portal fibrosis without septa), F2 (few septa), F3 (numerous septa without cirrhosis) and F4 (cirrhosis). The intensity of necroinflammation was graded on a scale as follows: A0 (no activity), A1 (mild activity), A2 (moderate activity) and $\mathrm{A} 3$ (severe activity).

In addition, HSS and HC + HSS patients had their degree of fibrosis analysed by ultrasonography according to the Cairo scoring system (WHO 1990) as follows: degree I (mild periportal fibrosis), degree II (moderate periportal fibrosis) and degree III (severe periportal fibrosis).

Determination of serum levels of biological markers - Blood samples $(15 \mathrm{~mL})$ were collected using a vacuum system and disposable needles from all patients and control group individuals for assessing the serum levels of biological markers.

In this study, the biological markers were divided into biochemical markers, platelets and cytokines involved with inflammation and fibrogenesis.

Determination of serum levels of biochemical markers - The following markers were assessed for the study: alanine aminotransferase (ALT), aspartate aminotransferase (AST), total proteins, bilirubins, $\gamma$-glutamil transferase $(\gamma-\mathrm{GT})$ and alkaline phosphatase (AP).

The serum levels of ALT, AST, total proteins, bilirubins, $\gamma$-GT and AP were determined by the ARCHITECT c8000 (Abbott) using Abbott reagent kits at the laboratory of the Hospital das Clínicas da UFPE.

Platelet count - Platelet counts were determined using the Cell-Dyn 3500 (Abbott) at the laboratory of the HC-UFPE.

Determination of cytokine serum levels - The serum levels of cytokines IL-13, IFN- $\gamma$, TNF- $\alpha$ and TGF- $\beta$ were measured using the enzyme linked immunosorbent assay Quantikine kit (R\&D system) following the manufacturer's instructions.

Statistical methods - HC and HC + HSS patients were divided into two groups according to the severity of their histological lesions: no significant or mild fibrosis (F0-F1) and significant or severe fibrosis (F2-F4). The primary outcome was the identification of patients with clinically significant fibrosis. This dichotomization was performed because F2 fibrosis is generally considered the threshold for the initiation of antiviral treatment of chronic HC.

These patients were also analysed according to the presence of necroinflammatory activity and divided into two groups: no significant activity (A0-A1) and significant activity (A2-A3). 
HSS and HC + HSS patients were statistically analysed into two groups according to the degree of fibrosis as evaluated by ultrasonography as follows: mild fibrosis (degree I) and severe fibrosis (degrees II and III).

The statistical analyses were performed using the software SPSS for Windows version 12.0, 2004 (Chicago, USA). P values of 0.05 or less were considered significant.

The ANOVA was used for comparison of serum levels of biological markers between the four study groups.

For every biological marker, receiving operating characteristics (ROC) curves were built to establish the best cut-off value that would correlate with severe fibrosis and severe necroinflammatory activity for each group of patients studied.

\section{RESULTS}

Biological serum marker levels - For the HC + HSS group (Table I), serum levels of AST, ALT, AP and $\gamma$-GT were higher in comparison to the control group ( $p$ $=0.001, p=0.014, p=0.029$ and $p=0.003$, respectively). In addition, the serum levels of AST were higher in comparison to the HSS group $(p=0.035)$. Also, the AP levels were higher than in the HC group $(p=0.023)$. Total and direct bilirubins were higher when compared with the HC group and control group $(\mathrm{p}<0.001$ for both) (Table II).

Levels of $\gamma$-globulin (Table III) were also higher in the HC + HSS group in comparison to the HC $(p<0.001)$ and HSS $(\mathrm{p}=0.035)$ groups, as well as the control group $(p<0.001)$. Albumin levels (Table III) were lower in the HC + HSS group than in the HC group $(\mathrm{p}=0.014)$, HSS group $(p=0.013)$ and control group $(p<0.001)$.

For the HC group (Table I), ALT levels were higher than in the HSS $(p=0.010)$ and control groups $(p<$ $0.001)$. AP and $\gamma$-GT were lower than in the HSS group $(p=0.012$ for both). In addition, AST levels were higher than in the control group $(\mathrm{p}=0.004)$. Also, $\gamma$-GT levels were higher than in the control group $(\mathrm{p}=0.028)$. Total bilirubins (Table II) in the HC group were higher when compared with the control group $(\mathrm{p}<0.013)$ mainly due to indirect bilirubin $(\mathrm{p}=0.023)$.

The HSS group compared with control group showed higher levels of AP, $\gamma$-GT (Table I), TB (Table II) and $\gamma$-globulins (Table I) $(\mathrm{p}=0.013, \mathrm{p}<0.001, \mathrm{p}=0.001$ and $\mathrm{p}=0.043$, respectively).

Serum levels of the cytokines IL-13, TGF- $\beta$, IFN- $\gamma$ and TNF- $\alpha$ were not significantly different among the study groups $(\mathrm{p}>0.05)$.

Correlation of biological serum marker levels to predict severe fibrosis and necroinflammatory activity in HC patient groups - Fibrosis stages and necroinflammatory activity grades obtained through histologies of liver biopsy using the Metavir scoring system were studied as described in the Patients, Materials and Methods section. Our results showed that $47.2 \%$ of HC patients had mild fibrosis and necroinflammatory activity and $52.8 \%$ had severe fibrosis and necroinflammatory activity.

When we compared the area under the curve (AUC) for the ROC of the serum levels of the biological markers in order to predict mild or severe fibrosis, it was found
TABLE I

Comparisons of the study groups with alanine aminotransferase (ALT), aspartate aminotransferase (AST), alkaline phosphatase (AP) and $\gamma$-glutamil transferase $(\gamma$-GT) levels

\begin{tabular}{lcccc}
\hline & \multicolumn{4}{c}{$\mathrm{p}$ value } \\
\cline { 2 - 5 } Groups & ALT & AST & AP & $\gamma$-GT \\
\hline HC/HSS x HC & 0.119 & 0.375 & $0.023^{a}$ & 0.182 \\
HC/HSS x HSS & 0.208 & $0.035^{a}$ & 0.502 & 0.173 \\
HC/HSS x control & $0.014^{a}$ & $0.001^{a}$ & $0.029^{a}$ & $0.003^{a}$ \\
HC x HSS & $0.010^{a}$ & 0.100 & $0.012^{a}$ & $0.012^{a}$ \\
HC x control & $<0.001^{a}$ & $0.004^{a}$ & 0.633 & $0.028^{a}$ \\
HSS x control & 0.330 & 0.384 & $0.013^{a}$ & $<0.001^{a}$ \\
\end{tabular}

$a$ : $(\mathrm{p}<0.05)$ is considered statistically significant; control: control group; HC: hepatitis C patients; HC/hepatitis C plus hepatosplenic schistosomiasis (HSS) patients.

\section{TABLE II}

Comparisons of the study groups with total bilirubins (TB), direct bilirubins (DB) and indirect bilirubins (IB) levels

\begin{tabular}{lccc}
\hline & \multicolumn{3}{c}{$\mathrm{p}$ value } \\
\cline { 2 - 4 } Groups & $\mathrm{TB}$ & $\mathrm{DB}$ & $\mathrm{IB}$ \\
\hline HC/HSS x HC & $<0.001^{a}$ & $<0.001^{a}$ & $0.038^{a}$ \\
HC/HSS x HSS & 0.305 & 0.123 & 0.704 \\
HC/HSS x control & $<0.001^{a}$ & $<0.001^{a}$ & $<0.001^{a}$ \\
HC x HSS & 0.077 & 0.083 & 0.216 \\
HC x control & $0.013^{a}$ & 0.113 & $0.023^{a}$ \\
HSS x control & $0.001^{a}$ & $0.008^{a}$ & $0.006^{a}$ \\
\hline
\end{tabular}

$a:(\mathrm{p}<0.05)$ is considered statistically significant; control: control group; HC: hepatitis C patients; HC/hepatitis C plus hepatosplenic schistosomiasis (HSS) patients.

\section{TABLE III}

Comparisons of the study groups with albumin and $\gamma$-globulin levels

\begin{tabular}{lcc}
\hline & \multicolumn{2}{c}{ p value } \\
\cline { 2 - 3 } Groups & Albumin & $\gamma$-globulin \\
\hline HC/HSS x HC & $0.014^{a}$ & $<0.001^{a}$ \\
HC/HSS x HSS & $0.013^{a}$ & $0.035^{a}$ \\
HC/HSS x control & $<0.001^{a}$ & $<0.001^{a}$ \\
HC x HSS & 0.422 & 0.549 \\
HC x control & $0.004^{a}$ & $0.046^{a}$ \\
HSS x control & 0.124 & $0.043^{a}$ \\
\hline
\end{tabular}

$a:(\mathrm{p}<0.05)$ is considered statistically significant; control: control group; HC: hepatitis C patients; HC/hepatitis C plus hepatosplenic schistosomiasis (HSS) patients. 
that TNF- $\alpha$ and AP showed statistically significant AUC $(\mathrm{p}=0.020$ and $\mathrm{p}=0.005$, respectively). The best diagnostic values of these markers (cut-offs) were reported using sensitivity, specificity, positive predictive value and negative predictive value and are shown in Table IV.

For the prediction of severe necroinflammatory activity, AST, AP and $\gamma$-GT showed statistically significant AUC. The best cut-off levels and diagnostic values of these markers can be seen in Table V.

Correlation of biological marker serum levels to predict severe fibrosis and severe necroinflammatory activity in the HC plus schistosomiasis group - In this group of patients, the gold-standard classification of fibrosis stage was the histology of liver biopsies using the Metavir scoring system, since only a small number of patients had ultrasonography data (5 patients missing data).

Our results showed that $31.2 \%$ of $\mathrm{HC}+\mathrm{HSS}$ patients had mild fibrosis and necroinflammatory activity and $68.8 \%$ had severe fibrosis and necroinflammatory activity.

When analysing the results, we found that total bilirubin showed a statistically significant AUC ROC curves for predicting severe fibrosis (Table VI). In addition, platelets, ALT, AST, total bilirubin and $\gamma$-globulin showed statistically significant AUC ROC curves for predicting severe necroinflammatory activity in these patients (Table VII).

Correlation of biological marker serum levels to predict severe fibrosis in the schistosomiasis patient group - The degree of fibrosis analysed through ultrasonography using the Cairo scoring system, as described in the Patients, Materials and Methods section, was compared with biological marker serum levels.

Of schistosomiasis patients, $90.9 \%$ presented with severe fibrosis according to ultrasonography analysis.

Platelet counts were used to build ROC curves to predict severe fibrosis in schistosomiasis patients. The results showed no statistically significant AUC ROC curves. The other biological markers could not be analysed due to the small number of patients.

Comparative analysis between $H C$ and $H C+H S S$ groups and HSS and HC $+H S S$ groups relative to fibrosis degree - Our results showed no statistically significant differences when we compared the degree of fibrosis among the study groups $(\mathrm{p}>0.05)$.

\section{DISCUSSION}

Hepatic fibrosis in $\mathrm{HC}$ and schistosomiasis co-infections can progress to cirrhosis and its complications, such as hepatocellular carcinoma (Köpke-Aguiar et al. 2002, Myers et al. 2002, Shiha \& Zalata 2002, Kamal et al. 2006).

The assessment of the presence and severity of liver fibrosis is essential in determining treatment strategies, response to treatment, prognosis and the potential risk for complications in patients with chronic liver disease.

Liver biopsy, the gold-standard method for diagnosing the severity of necroinflammatory activity and fibrosis, is an invasive tool and it is associated with rare but serious complications, such as bleeding, pneumothorax and perforation of the colon and gallbladder (Thuluvath

TABLE IV

Performance of biological markers to discriminate between no significant or mild fibrosis and significant or severe fibrosis in hepatitis $\mathrm{C}$ patients group

\begin{tabular}{lcccccc}
\hline Biomarker & $\begin{array}{c}\text { Area under } \\
\text { curve }\end{array}$ & Cut-off & $\begin{array}{c}\text { Sensitivity } \\
(95 \% \mathrm{CI})\end{array}$ & $\begin{array}{c}\text { Specificity } \\
(95 \% \mathrm{CI})\end{array}$ & $\begin{array}{c}\text { Positive predictive } \\
\text { value (\%) }\end{array}$ & $\begin{array}{c}\text { Negative predictive } \\
\text { value (\%) }\end{array}$ \\
\hline TNF- $\alpha$ & 0.728 & $\geq 3.23$ & 63.16 & 88.24 & 85.71 & 68.18 \\
Alkaline phosphatase & 0.774 & $\geq 11.90$ & 84.21 & 58.82 & 69.57 & 76.92 \\
\hline
\end{tabular}

only the discriminative tests are displayed; CI: confidence interval.

TABLE V

Performance of biological markers to discriminate between no significant activity necroinflammatory and significant activity necroinflammatory in hepatitis $\mathrm{C}$ patients group

\begin{tabular}{lcccccc}
\hline Biomarker & $\begin{array}{c}\text { Area under } \\
\text { curve }\end{array}$ & Cut-off & $\begin{array}{c}\text { Sensitivity } \\
(95 \% \text { CI })\end{array}$ & $\begin{array}{c}\text { Specificity } \\
(95 \% \text { CI) }\end{array}$ & $\begin{array}{c}\text { Positive predictive } \\
\text { value (\%) }\end{array}$ & $\begin{array}{c}\text { Negative predictive } \\
\text { value (\%) }\end{array}$ \\
\hline Aspartate aminotransferase & 0.8 & $\geq 47.5$ & 84.21 & 70.59 & 76.19 & 80 \\
Alkaline phosphatase & 0.833 & $\geq 104$ & 63.16 & 100 & 100 & 70.83 \\
$\gamma$-glutamil transferase & 0.707 & $\geq 107$ & 52.63 & 88.24 & 83.33 & 62.13 \\
\hline
\end{tabular}

only the discriminative tests are displayed; CI: confidence interval. 
\& Krok 2006). Furthermore, because of its risks, cost and inconvenience, liver biopsy is certainly not the ideal procedure for repeated assessment of disease progression, especially during chronic HC (Castera et al. 2008, Fontana et al. 2008).

In light of this, developing non-invasive tests that can accurately predict fibrosis stage and progression over time is a high priority and a growing medical necessity. Among these non-invasive tests are biological markers in serum, used either individually or in combination and alternative imaging techniques, such as ultrasound, magnetic resonance imaging and transient elastography (Sandrin et al. 2003, Ziol et al. 2005, Gressner et al. 2007, Castera et al. 2008).

Conventional liver function tests reflect hepatocyte damage as ALT and AST, whereas biliary obstructions can be studied by bilirubin and AP and biosynthetic function by albumin and prothrombin time. Although these tests provide important information on some aspects of liver function, they do not assess the activity of the fibrogenic process, but can indicate the stage of fibrosis (Gressner et al. 2007, Rossi et al. 2007).

However, biomarkers that have a direct relation to extracellular matrix protein synthesis or turnover, such as the amino-terminal peptide of III procollagen, are believed to primarily reflect fibrogenesis activity (Gressner et al. 2007).

Recent studies suggest that some of these biological serum markers of fibrosis, used in combination to form fibrosis scores, such as Fibrotest and Actitest (Poynard et al. 2002, 2004, 2005), Forns index (Forns et al. 2002) and AST/platelets ratio (Wai et al. 2003), may provide important disease staging information like the presence or absence of advanced fibrosis or cirrhosis. Although widely available, these scores have been found to be poor at predicting intermediate levels of fibrosis and there is a risk of false-positive and false-negative results (Poynard et al. 2005).

Most scores were developed and tested in HCV patients and, thus, their extrapolation to non-HCV aetiologies of fibrosis must be considered with caution (Gressner et al. 2007).

In this context, this study aimed to evaluate biological serum markers that could be used to predict the severity of liver fibrosis in $\mathrm{HC}$ and schistosomiasis as isolated diseases or co-infections.

According to Kamal et al. (2004, 2006), patients with $\mathrm{HC}$ and schistosomiasis co-infections exhibit higher necroinflammatory and hepatic fibrosis in liver biopsies with a significant hepatic fibrosis progression rate compared with HCV infection alone. They also found that levels of fibrosis markers and cytokines evaluated in this study showed a strong correlation with disease progression. Our results showed no statistically significant differences in fibrosis degree on histology evaluation when fibrosis of $\mathrm{HC}+\mathrm{HSS}$ patients were compared to $\mathrm{HC}$ patients alone. In addition, no statistically significant differences were found comparing fibrosis degree by ultrasonography in HC + HSS and HSS groups. However, higher levels of fibrosis serum markers, such as AST,

TABLE VI

Performance of biological markers to discriminate between no significant or mild fibrosis and significant or severe fibrosis in hepatitis C plus schistosomiasis patients group

\begin{tabular}{lcccccc}
\hline Biomarker & $\begin{array}{c}\text { Area under } \\
\text { curve }\end{array}$ & Cut-off & $\begin{array}{c}\text { Sensitivity } \\
(95 \% \mathrm{CI})\end{array}$ & $\begin{array}{c}\text { Specificity } \\
(95 \% \mathrm{CI})\end{array}$ & $\begin{array}{c}\text { Positive predictive } \\
\text { value }(\%)\end{array}$ & $\begin{array}{c}\text { Negative predictive } \\
\text { value }(\%)\end{array}$ \\
\hline Total bilirubins & 0.845 & $\geq 1.05$ & 72.73 & 100 & 100 & 62.5 \\
\hline
\end{tabular}

only the discriminative tests are displayed; CI: confidence interval.

\section{TABLE VII}

Performance of biological markers to discriminate between no significant activity necroinflammatory and significant activity necroinflammatory in hepatitis $\mathrm{C}$ plus schistosomiasis patients group

\begin{tabular}{lcccccc}
\hline Biomarker & $\begin{array}{c}\text { Area under } \\
\text { curve }\end{array}$ & Cut-off & $\begin{array}{c}\text { Sensitivity } \\
(95 \% \mathrm{CI})\end{array}$ & $\begin{array}{c}\text { Specificity } \\
(95 \% \mathrm{CI})\end{array}$ & $\begin{array}{c}\text { Positive predictive } \\
\text { value (\%) }\end{array}$ & $\begin{array}{c}\text { Negative predictive } \\
\text { value (\%) }\end{array}$ \\
\hline Platelets & 0.909 & $\leq 195$ & 100 & 80 & 91.67 & 100 \\
Alanine aminotransferase & 0.836 & $\geq 41.5$ & 100 & 60 & 84.62 & 100 \\
Aspartate aminotransferase & 0.809 & $\geq 88.5$ & 54.55 & 100 & 100 & 50 \\
Globulin & 0.855 & $\geq 1.76$ & 81.82 & 100 & 100 & 71.43 \\
\hline
\end{tabular}

only the discriminative tests are displayed; CI: confidence interval. 
AP, bilirubin and $\gamma$-globulin, were found in $\mathrm{HC}+\mathrm{HSS}$ patients in comparison with HC and HSS alone, suggesting that these markers could differentiate co-infected from the mono-infected patients (Kamal et al. 2006).

In addition, HC patients produced higher levels of ALT in comparison to HSS patients, indicating that necroinflammatory activity and viral replication is present in this infection (Pal et al. 2006).

Levels of $\gamma$-GT and AP were higher in HSS patients in comparison to $\mathrm{HC}$ patients. Increased $\gamma$-GT serum levels in HSS patients may be due the presence of granulomas in the hepatic parenchyma. The AP levels in HSS patients are also related to the presence of granulomas in the hepatic parenchyma and distortion of the vasculature (Barreto 1971, Vianna et al. 1989). These granulomas could eventually produce a biliary duct compression by raising the levels of $\gamma$-GT and this enzyme could be an early marker of portal hypertension (Martins \& Borges 1993, Souza et al. 2000, Köpke-Aguiar et al. 2002).

According to our results, $\gamma$-GT serum levels were also capable of differentiating between mild and severe necroinflammatory activity in $\mathrm{HC}$ patients with a predictive positive value of $83 \%$. An explanation for this association was not found because levels of this enzyme are normally related to severe fibrosis and early cholestasis (Martins \& Borges 1993, Imbert-Bismut et al. 2001).

Serum levels of the cytokines IL-13, INF- $\gamma$, TNF- $\alpha$ and TGF- $\beta$ were not significantly different among the study groups $(p>0.05)$.

Analysing fibrosis stage and necroinflammatory activity in each group of patients separately, keeping in mind that patients with $\mathrm{F} 2$ fibrosis/A2 activity or greater are candidates for antiviral therapy, we found in the $\mathrm{HC}$ group that TNF- $\alpha$ and AP could differentiate between mild and severe hepatic fibrosis and that AST, AP and $\gamma$-GT could differentiate between mild and severe necroinflammatory activity.

TNF- $\alpha$ levels in HC patients have been correlated with hepatic inflammation (Neuman et al. 2002, Kamal et al. 2006) and our study showed the association of this cytokine with severe hepatic fibrosis.

AP serum levels could be used as a biological marker for both severe fibrosis and necroinflammatory activity in $\mathrm{HC}$ patients. In other studies, AP has also been associated with $\mathrm{HC}$ cirrhosis, where fibrosis and inflammation may be more severe (Fontana \& Lok 2002).

We demonstrated an association between platelet counts and severe activity in HC + HSS patients, with a cut-off level of $\leq 195.000 / \mathrm{mm}^{3}$. A moderate decrease in platelet count is a marker of portal hypertension present in the HSS group and is also a good predictive marker of cirrhosis in HCV infection (Renou et al. 2000, Souza et al. 2000).

In conclusion, our results suggest the inclusion of some biological serum marker levels determination in clinical practice, prognosis and management of $\mathrm{HC}$ and schistosomiasis patients and this may be helpful for the diagnosis of fibrosis degree and necroinflammatory activity. These may not yet be used as a substitute, but as a tool to avoid repeated liver biopsy. However, currently available biological serum markers should be used with caution since neither single nor sets of markers fulfil the requirements of an ideal non-invasive biomarker of fibrosis that is liver-specific, easy to perform, reliable, reproducible with low inter-laboratory variability and cost-effective. Even the best and most evaluated markers do not meet the criteria of an ideal marker.

The future goals of our group are to increase the number of subjects in the HC, HC + HSS and HSS groups and to build a fibrosis index with the markers analysed in this present study to improve diagnostic values and accurately measure the degree of liver fibrosis and necroinflammatory activity in these diseases. Furthermore, we aim to correlate these biological markers with other chronic liver diseases and measure the clinical evolution after treatment.

\section{REFERENCES}

Abath FG, Morais CN, Montenegro CE, Wynn TA, Montenegro SM 2006. Immunopathogenic mechanisms in schistosomiasis: what can be learnt from human studies? Trends Parasitol 22: 85-91.

Andrade ZA 1962. A hepatite crônica esquistossomótica. Hospital (Rio J) 62: 563-564.

Barreto VS 1971. Alkaline phosphatase in schistosomiasis. Ann Intern Med 74: 450-451.

Bedossa P, Poynard T 1996. An algorithm for the grading of activity in chronic hepatitis C. The Metavir Cooperative Study Group. Hepatology 24: 289-293.

Burchard GD, Guissé-Sow F, Diop M, Ly A, Lanuit R, Gryseels B, Gressner AM 1998. Schistosoma mansoni infection in a recently exposed community in Senegal: lack of correlation between liver morphology in ultrasound and connective tissue metabolites in serum. Trop Med Int Health 3: 234-241.

Castera L, Forns X, Alberti A 2008. Non-invasive evaluation of liver fibrosis using transient elastrography. J Hepatol 48: 835-847.

Cid LV, Sarno EN, Zaltman C, Ahmed EO, da Silva JC, Silveira JP, Abdalla P 1985. Anastomose espleno-renal seletiva e hepatite pós-transfusional: seguimento a curto e médio prazos. Arq Gastroenterol 22: 109-112.

Correia HS, Domingues AL, Lopes EP, Morais CN, Sarteschi C, Moura IM 2009. Níveis séricos de globulinas e intensidade da fibrose hepática em pacientes com esquistossomose mansônica. Arq Gastroenterol 46: 194-198.

Dusek J, Kubasta M, Kodousek R, Kubastova B 1965. Needle biopsy of the liver in schistosomiasis mansoni: the value of histological examination. J Trop Med Hyg 68: 189-195.

Fontana RJ, Goodman ZD, Dienstag JL, Bonkovsky HL, Naishadham D, Sterling RK, Su GL, Ghosh M, Wright EC, HALT-C Trial Group 2008. Relationship of serum fibrosis markers with liver fibrosis stage and collagen content in patients with advanced chronic hepatitis C. Hepatology 47: 789-798.

Fontana RJ, Lok AS 2002. Noninvasive monotoring of patients with chronic hepatitis C. Hepatology 36 (Suppl. 1): 57-64.

Forns X, Ampurdanès S, Llovet JM, Aponte J, Quintó L, MartínezBauer E, Bruguera M, Sánchez-Tapias JM, Rodés J 2002. Identification of chronic hepatitis $\mathrm{C}$ patients without hepatic fibrosis by a simple predictive model. Hepatology 36: 986- 992.

Freeman AJ, Law MG, Kaldor JM, Dore GJ 2003. Predicting progression to cirrhosis in chronic hepatitis $\mathrm{C}$ virus infection. $J$ Viral Hepat 10: 285-293. 
Gressner OA, Weiskirchen R, Gressner AM 2007. Biomarkers of hepatic fibrosis, fibrogenesis and genetic pre-disposition pending between fiction and reality. J Cell Mol Med 11: 1031-1051.

Gretch DR 1997. Use and interpretation of HCV diagnostic tests in the clinical setting. Clin Liver Dis 1: 543-557.

Imbert-Bismut F, Ratziu V, Pieroni L, Charlotte F, Benhamou Y, Poynard T, Multivirc Group 2001. Biochemical markers of liver fibrosis in patients with hepatitis $\mathrm{C}$ virus infection: a prospective study. Lancet 357: 1069-1075.

Kamal SM, Graham CS, He Q, Bianchi L, Tawil AA, Rasenack JW, Khalifa KA, Massoud MM, Koziel MJ 2004. Kinetics of intrahepatic hepatitis $\mathrm{C}$ virus (HCV)- specific $\mathrm{CD}^{+} \mathrm{T}$ cell responses in $\mathrm{HCV}$ and Schistosoma mansoni coinfection: relation to progression of liver fibrosis. J Infect Dis 189: 1140-1150.

Kamal SM, Turner B, He Q, Rasenack J, Bianchi L, AI Tawil A, Nooman A, Massoud M, Koziel MJ, Afdhal NH 2006. Progression of fibrosis in hepatitis $\mathrm{C}$ with and without schistosomiasis: correlation with serum markers of fibrosis. Hepatology 43: 771-779.

Köpke-Aguiar LA, Martins JR, Passerotti CC, Toledo CF, Nader HB, Borges DR 2002. Serum hyaluronic acid as a comprehensive marker to assess severity of liver disease in schistosomiasis. Acta Trop 84: 117-126.

Lichtinghagen R, Bahr MJ 2004. Noninvasive diagnosis of fibrosis in chronic liver disease. Expert Rev Mol Diagn 4: 715-726.

Martins RD, Borges DR 1993. Ethanol challenge in non-alcoholic patients with schistosomiasis. J Clin Pathol 46: 250-253.

Missale G, Bertoni R, Lamonaca V, Valli A, Massari M, Mori C, Rumi MG, Houghton M, Fiaccadori F, Ferrari C 1996. Different clinical behaviors of acute hepatitis $\mathrm{C}$ virus infection are associated with different vigor of the anti-viral cell-mediated immune response. J Clin Invest 98: 706-714.

Morais CN, Carvalho BM, Melo WG, Lopes EP, Domingues AL, Jucá NT, Souza W, Abath FG, Montenegro SM 2006. Preliminar evaluation of cytokines in the hepatitis $\mathrm{C}$-schistosomiasis co-infection. Mem Inst Oswaldo Cruz 101 (Suppl. I): 353-354.

Myers RP, Ratziu V, Imbert-Bismut F, Charlotte F, Poynard T, Multivirc Group 2002. Biochemical markers of liver fibrosis: a comparison with historical features in patients with chronic hepatitis C. Am J Gastroenterol 97: 2419-2425.

Neuman MG, Benhamou JP, Bourliere M, Ibrahim A, Malkiewicz I, Asselah T, Martinot-Peignoux M, Shear NH, Katz GG, Akremi R, Benali S, Boyer N, Lecomte L, Le Breton V, Le Guludec G, Marcellin P 2002. Serum tumour necrosis factor- $\alpha$ and transforming growth factor- $\beta$ levels in chronic hepatitis $\mathrm{C}$ patients are immunomodulated by therapy. Cytokine 17: 108-117.

Pal S, Shuhart MC, Thomassen L, Emerson SS, Su T, Feuerborn N, Kae J, Gretch DR 2006. Intrahepatic hepatitis C virus replication correlates with chronic hepatitis $\mathrm{C}$ disease severity in vivo. $J$ Virol 80: 2280-2290.

Pessione F, Degos F, Marcellin P, Duchatelle V, Njapoum C, MartinotPeignoux M, Degott C, Valla D, Erlinger S, Rueff B 1998. Effect of alcohol consumption on serum hepatitis $\mathrm{C}$ virus RNA and histological lesions in chronic hepatitis C. Hepatology 27: 1717-1722.

Poynard T, Imbert-Bismut F, Munteanu M, Ratziu V 2005. FibroTestFibroSURE: towards a universal biomarker of liver fibrosis? $E x$ pert Rev Mol Diagn 5: 15-21.

Poynard T, Imbert-Bismut F, Ratziu V, Chevret S, Jardel C, Moussalli
J, Messous D, Degos F, GERMED cyt04 group 2002. Biochemical markers of liver fibrosis in patients infected by hepatitis $C$ virus: longitudinal validation in a randomized trial. J Viral Hepat 9: 128-133.

Poynard T, Munteanu M, Imbert-Bismut F, Charlotte F, Thabut D, Le Calvez S, Messous D, Thibault V, Benhamou Y, Moussalli J, Ratziu V 2004. Prospective analysis of discordant results between biochemical markers and biopsy in patients with chronic hepatitis C. Clin Chem 50: 1344-1355.

Poynard T, Yuen MF, Ratziu V, Lai CL 2003. Viral hepatitis C. Lancet 362: 2095-2100.

Renou C, Halfon P, Jouve E, Muller P, Bertrand JJ, Vitry JM, Benderitter T 2000. Relevance of moderate isolated thrombopenia as a strong predictive marker of cirrhosis in patients with chronic hepatitis $\mathrm{C}$ virus. Hepatology 32: 421A.

Ricard-Blum S, Hartmann DJ, Grenard P, Ravaoalimalala VE, Boisier P, Esterre P 1999. Relationships between several markers of extracellular matrix turn-over and ultrasonography in human schistosomiasis mansoni. Am J Trop Med Hyg 60: 658-663.

Rossi E, Adams LA, Bulsara M, Jeffrey GP 2007. Assessing liver fibrosis with serum marker models. Clin Biochem Rev 28: 3-10.

Sandrin L, Fourquet B, Hasquenoph JM, Yon S, Fournier C, Mal F, Christidis C, Ziol M, Poulet B, Kasemi F, Beaugrand M, Palau R 2003. Transient elastography: a new noninvasive method of assessment of hepatic fibrosis. Ultrasound Med Biol 29: 1705-1713.

Shiha G, Zalata KR 2002. Does schistosomiasis interfere with application of the Knodell score for assessment of chronic hepatitis $\mathrm{C}$ ? Med Sci Monit 8: CR72-77.

Souza MR, Toledo CF, Borges DR 2000. Thrombocytemia as a predictor of portal hypertension in schistosomiasis. Dig Dis Sci 45: 1964-1970.

Strauss E 2001. Hepatite C. Rev Soc Bras Med Trop 34: 69-82.

Stuyver L, Wyseur A, van Arnhem W, Hernandez F, Maertens G 1996. Second-generation line probe assay for hepatitis C virus genotyping. J Clin Microbiol 34: 2259-2266.

Thuluvath PJ, Krok KL 2006. Noninvasive markers of fibrosis for longitudinal assessment of fibrosis in chronic liver disease: are they ready for prime time? Am J Gastroenterol 101: 1497-1499.

Vianna MR, Gayotto LC, Telma R, Santos M, Alves VA, Fukushima $\mathrm{J}$, de Brito T 1989. Intrahepatic bile duct changes in human hepatosplenic schistosomiasis mansoni. Liver 9: 100-109.

Wai CT, Greenson JK, Fontana RJ, Kalbfleisch JD, Marrero JA, Conjeevaram HS, Lok AS 2003. A simple noninvasive index can predict both significant fibrosis and cirrhosis in patients with chronic hepatitis C. Hepatology 38: 518-526.

WHO - World Health Organization 1991. Proposal for a practical guide to the standardized use of ultrasound in the assessment of pathological changes. In Meeting on ultrasonography in schistosomiasis, TDR/SCH/Ultrason, Cairo, Egypt, 32 pp.

Zeuzem S, Rüster B, Roth WK 1994. Clinical evaluation of a new polymerase chain reaction assay (Amplicor $\mathrm{HCV}$ ) for detection of hepatitis C virus. Z Gastroenterol 32: 342-347.

Ziol M, Handra-Luca A, Kettaneh A, Christidis C, Mal F, Kasemi F, de Lédinghen V, Marcellin P, Dhumeaux D, Trinchet JC, Beaugrand M 2005. Noninvasive assessment of liver fibrosis by measurement of stiffness in patients with chronic hepatitis C. Hepatology 41: 48-54. 